\title{
A Single Arm, Monocentric, Prospective, Open Label Study to Evaluate Anti-Ageing Efficacy of Human Growth Factors and Cytokines Containing Cosmetic Skin Serum in Indian Female Population
}

\author{
Mukta Sachdev1,2, Anoop Chullikana ${ }^{3}$, Raviraja N. Seetharam³, Rachana Shilpakar2, R. Sapna ${ }^{2}$, \\ Keerthi Velugotla², Ritambhara², Anish S. Majumdar3, Pawan Kumar Gupta ${ }^{3 *}$
}

${ }^{1}$ Manipal Hospital, Bangalore, India

${ }^{2}$ MS Skin Centre, Bangalore, India

${ }^{3}$ Stempeutics Research Pvt. Ltd., Bangalore, India

Email: *pawan.gupta@stempeutics.com

How to cite this paper: Sachdev, M., Chullikana, A., Seetharam, R.N., Shilpakar, R., Sapna, R., Velugotla, K., Ritambhara, Majumdar, A.S. and Gupta, P.K. (2017) A Single Arm, Monocentric, Prospective, Open Label Study to Evaluate Anti-Ageing Efficacy of Human Growth Factors and Cytokines Containing Cosmetic Skin Serum in Indian Female Population. Journal of Cosmetics, Dermatological Sciences and Applications, 7, 118-132.

https://doi.org/10.4236/jcdsa.2017.71011

Received: February 24, 2017

Accepted: March 25, 2017

Published: March 28, 2017

Copyright $\odot 2017$ by authors and Scientific Research Publishing Inc. This work is licensed under the Creative Commons Attribution International License (CC BY 4.0).

http://creativecommons.org/licenses/by/4.0/

\begin{abstract}
Introduction: The use of growth factors and cytokines in skin rejuvenation and reversal of photo ageing is a novel anti-ageing treatment. These factors provide a microenvironment that seems to favor tissue repair and regeneration. Methods: An open label, monocentric, single arm study to evaluate anti-ageing efficacy of conditioned medium obtained from adult human bonemarrow derived allogenic mesenchymal stromal cells (BMMSC) along with excipients formulated into a cosmetic serum, was conducted in 40 Indian female population aged 35 to 60 years, belonging to skin type IV - VI of Norwood Scale for a duration of 90 days. Parameters-fine lines, wrinkles, crow's feet, evenness of skin tone, skin firmness/laxity, hydration of skin, homogeneity of age spots, and visible pores were used to evaluate the anti-ageing and rejuvenating properties of the test product. Results and Discussion: Improvement was seen in majority of parameters starting from 15 - 30 days. Product was safe and well tolerated as per the dermatologist and subjects' self-assessment.
\end{abstract}

\section{Keywords}

Cytokines, Conditioned Media, Crow's Feet, Anti-Ageing

\section{Introduction}

Ageing is a natural and multidimensional process concerned with physiological, 
cellular and social changes of an organism over a period of time. Internal factors like genetics, hormones, metabolism and external factors like sun exposure, radiation and toxins contribute to ageing [1]. Some explanations for inevitable natural aging are cell damage by reactive oxygen species, mitochondrial dysfunction, and shorting of telomeres in successive cell division [2]. Aging in the sun exposed parts is typically characterized by wrinkling, laxity and roughness [3] [4]. Growth factor supplementation for preventing the aging of skin is an emerging concept. Stem cells release a host of growth factors into the conditioned medium (CM) used in culture [5]. Use of this conditioned medium in a suitable formulation could be used to prevent skin aging.

Cutisera ${ }^{\mathrm{TM}}$ contains the $\mathrm{CM}$ obtained from adult human bone marrow derived mesenchymal stromal cells (BMMSCs) along with excipients formulated into a cosmetic serum. Human mesenchymal stromal cells (MSCs) are known to secrete various types of growth factors and cytokines (GF/CK) that possess important biological functions. These GFs/CKs present in the CM secreted by BMMSCs grown under specific culture conditions promote generation of healthy skin, hair growth and wound healing. CM reportedly contains more than $200 \mathrm{GFs} / \mathrm{CKs}$. We have identified and qualified $30 \mathrm{GFs} / \mathrm{CKs}$ secreted by BMMSCs in our culture condition. Some of these factors have been implicated for their role in repair and regeneration of damaged tissue [6] [7] [8]. Using a novel production technology under Good Manufacturing Practice (GMP) conditions, homogenous CM is being consistently produced for developing the cosmetic product Cutisera ${ }^{\mathrm{TM}}$ to derive benefits for skin care.

\section{Materials and Methods}

\subsection{Study Design}

This was an open label, monocentric, single arm, efficacy study in Indian females in the age group 35 - 60 years (skin type IV - VI of Norwood Scale) with signs of ageing such as fine lines, wrinkles, age spots and uneven skin tone, willing to abstain from spa treatments, facials and other anti-ageing products.

The primary objective of the study was to evaluate the efficacy of twice daily (0.5 gm per dose) application of Cutisera ${ }^{\mathrm{TM}}$ over three months using the anti-ageing parameters: overall fine lines and wrinkles, crow's feet grading, evenness of skin tone, skin firmness/laxity, hydration of skin, homogenecity of age spots, and visible pores. The secondary objective was to assess product safety, tolerance and acceptability.

The study was conducted from July to October 2014 in accordance with ICHGCP (International Conference on Harmonization-Good Clinical Practice) guidelines. Ethics committee approval was obtained for the study. Informed consent was obtained from all subjects before screening. Subjects who satisfied eligibility criteria underwent skin sensitivity test to rule out sensitivity to the test product before including them in the study.

Subjects were asked to stop any facial product other than the provided Cetaphil Cleansing Lotion and Rivela Sunscreen Lotion SPF-50 (Cipla Pharmceuti- 
cals Ltd). Cutisera ${ }^{\mathrm{TM}}$ was applied twice daily (morning and evening) as follows: two pump ( $0.5 \mathrm{~g})$ of Cutisera ${ }^{\mathrm{TM}}$ was released on to the hand. Using index finger, the subjects applied small dots all over the face uniformly, then massaged well till it absorbed completely. First application of the product was conducted at the investigational site under the supervision of the study personnel.

\section{Subject Assessment and Visits}

- The study was conducted for a period of approximately 90 days for each subject. It included a total of 6 visits i.e., day 0 (screening), day 1 (baseline), day 15, day 30, day 60 and day 90 (follow up visits).

- Dermatologist's assessment for efficacy was done using dermatological assessment questionnaire. The various skin attributes assessed were overall fine lines and wrinkles, crow's feet grading, evenness of skin tone, skin firmness/laxity, hydration of skin, homogeneity of age spots, and visible pores for efficacy were done. The dermatologists grading scale is given in Table 1 . Subjects were asked to rate the condition of their skin using subject selfassessment questionnaire. The parameters assessed were overall wrinkles on the face, spots, uneven skin tone, firmness of skin, hydration of skin, visible pores on the face. The scores ranged from 0 to 4 for "none", "negligible", "mild", "moderate" and "severe".

- Dermatologist assessed application site reaction in terms of erythema, dryness, edema, urticaria, acneiform eruption, allergic reactions, and others. Subjects assessed application site reaction in terms of redness, dryness, itching, burning, pimple like eruptions, sweating, oiliness and any other. Each

Table 1. Dermatological assessment for efficacy.

\begin{tabular}{|c|c|c|c|c|c|c|c|c|}
\hline Parameter & $\begin{array}{c}\text { Crow's feet } \\
\text { Photo grading }\end{array}$ & & $\begin{array}{l}\text { Fine lines } \\
\text { and wrinkles }\end{array}$ & Evenness of skin tone & $\begin{array}{l}\text { Laxity } \\
\text { of skin }\end{array}$ & $\begin{array}{c}\text { Skin } \\
\text { Hydration }\end{array}$ & $\begin{array}{l}\text { Homogenicity } \\
\text { of age spots }\end{array}$ & Visible pores \\
\hline Score & Category & Score & Category & Category & Category & Category & Category & Category \\
\hline 0 & No wrinkle & 1 & $\begin{array}{l}\text { Very severe } \\
\text { wrinkles }\end{array}$ & $\begin{array}{l}\text { Very un-even toned } \\
\text { skin/highly heterogeneous } \\
\text { in colour across the face }\end{array}$ & Very loose & Highly dry & Very dark & $\begin{array}{l}\text { Photonumeric on a } \\
\text { six point scale where } \\
1=\text { minimum and } \\
6=\text { maximum }\end{array}$ \\
\hline 1 & $\begin{array}{l}\text { Very Fine } \\
\text { Wrinkle }\end{array}$ & 2 & $\begin{array}{c}\text { Severe } \\
\text { wrinkles }\end{array}$ & $\begin{array}{l}\text { Moderately un-even } \\
\text { toned skin/moderate } \\
\text { heterogenecity in colour } \\
\text { across the face }\end{array}$ & Loose & $\begin{array}{c}\text { Moderately } \\
\text { dry }\end{array}$ & $\begin{array}{c}\text { Moderately } \\
\text { dark }\end{array}$ & \\
\hline 2 & $\begin{array}{c}\text { Fine } \\
\text { Wrinkle }\end{array}$ & 3 & $\begin{array}{l}\text { Moderate } \\
\text { wrinkles }\end{array}$ & $\begin{array}{l}\text { Slightly even toned skin/ } \\
\text { moderate homogenecity } \\
\text { in colour across the face }\end{array}$ & $\begin{array}{l}\text { Slightly } \\
\text { firm }\end{array}$ & $\begin{array}{c}\text { Slightly } \\
\text { moisturized }\end{array}$ & Slightly light & \\
\hline 3 & $\begin{array}{l}\text { Moderate } \\
\text { Wrinkle }\end{array}$ & 4 & $\begin{array}{c}\text { Fine } \\
\text { wrinkles }\end{array}$ & $\begin{array}{l}\text { Moderately even toned } \\
\text { skin/moderate } \\
\text { homogenecity in colour } \\
\text { across the face }\end{array}$ & $\begin{array}{l}\text { Moderately } \\
\text { firm }\end{array}$ & $\begin{array}{l}\text { Moderately } \\
\text { moisturized }\end{array}$ & $\begin{array}{c}\text { Moderately } \\
\text { light }\end{array}$ & \\
\hline 4 & $\begin{array}{c}\text { Severe } \\
\text { Wrinkle }\end{array}$ & 5 & $\begin{array}{l}\text { Very fine } \\
\text { wrinkles }\end{array}$ & $\begin{array}{l}\text { Very Even toned skin/ } \\
\text { highly homogeneous in } \\
\text { colour across the face }\end{array}$ & Very firm & $\begin{array}{l}\text { Highly } \\
\text { moisturized }\end{array}$ & $\begin{array}{l}\text { Very light } \\
\text { (similar to } \\
\text { skin tone) }\end{array}$ & \\
\hline
\end{tabular}


parameter was assessed in score ranged from 0 to 4 (none, mild, moderate, severe, very severe), both by the dermatologist and the subject. Scores by dermatologists were averaged for each visit and changes from baseline were calculated. Shift in subject's self-assessment scores from higher severity to lower severity was considered as improvement and percentage of subjects who felt improvement was calculated.

- The standardized and specific non-invasive instruments Chromameter (Chroma Meter ${ }^{\circledast}$ CR-400 (Konica Minolta, Tokyo, Japan)), Cutometer ${ }^{\circledast} 580$ MPA, Corneometer ${ }^{\circledast}$ CM 825, Visioscan ${ }^{\circledast}$ VC 98 (all 3 from Courage-Khazaka, Cologne, Germany), Facial imaging using Image Pro II and Digital imaging have been used to measure the relevant parameters on baseline, day 30,60 and 90.

- Chromameter was used to measure skin colour on the exposed skin of cheek, forehead and covered skin of the inner arm as reference. It provides intensity of reflected light in the $\mathrm{L}^{*} \mathrm{a}^{*} \mathrm{~b}^{*}$ system of the ("Commission Internationale de l'Eclairage” (CIELab). L* represents luminance, a measure of reflected light. Three consecutive luminance $\left(\mathrm{L}^{\star}\right)$ values were taken at each site and averaged to get the value at that site. Values of both the cheek were averaged to get the final value for the cheek.

- Cutometer was used to assess skin elasticity. It consists of a probe with suction head which sucks the skin through an inlet port via negative pressure and then returns to its original shape after the pressure is removed. Various $\mathrm{R}$ parameters representative of skin elasticity and firmness is measured using light source. R2 and R5 value corresponds to overall and net elasticity of the skin, respectively. Closer the value is to 1.0, higher is the skin elasticity. R6 value represents visco-elasticity of the skin. Decrease in this value is a sign of improvement.

- Corneometer consists of a capacitance meter and measures hydration level of stratum corneum based on the change in dielectric constant because of change in skin surface hydration. Increase in values suggests better hydration of skin.

- Visio scan consists of a high resolution camera and UV-A light source for illumination of skin. It quantifies the wrinkles on the skin.

\subsection{Preparation of Cutisera ${ }^{\mathrm{TM}}$}

The conditioned medium was concentrated 10-fold (10X CM) using tangential flow filtration (TFF) technique, an efficient method for separation, purification, and concentration of biomolecules/proteins. This process uses a pump to circulate the conditioned medium across the surface of membranes with a $1 \mathrm{kDa}$ cut-off filters housed in a multilevel structure (cassette) thus giving a tangential flow which acts as the driving force to transport solute and small molecules through the membrane. The cross flow of liquid concentrates the conditioned media to 10-fold, which was used as an active ingredient in Cutisera ${ }^{\mathrm{TM}}$. A unique combination of excipients was developed in the formulation containing tighten- 
ing \& moisturizing agents, preservative, viscosity increasing agent and emollient in order to preserve the biological activities of active ingredient.

\subsection{Statistical Analysis}

Total of 40 subjects were planned to be enrolled in the study. Results of the study are summarized with summary statistics, including average and standard deviation (SD) for continuous variables and frequency and percentages for categorical variables. Paired t-test was used for analyzing change from baseline to each visit for continuous variables. Chi-square test has been used to analyze data involving proportions. $\mathrm{P}<0.05$ was considered statistically significant.

\section{Results}

A total of 40 subjects were enrolled in the study. The subjects were equally distributed based on their skin type (normal, oily, dry and combination). Thirty eight subjects completed the study. Site application reaction by dermatological evaluation for product tolerance showed that one subject had mild dryness at baseline and day 30 . One subject had mild acneiform eruption at day 15 and day 30. Frequency and severity of the noted reactions were neither clinically significant nor required any medical intervention. Site application reaction reported by the subjects based on self-evaluation for product tolerance is as follows: Mild itching, mild burning sensation, severe sweating (one subject each), Mild oiliness (two subjects), moderate oiliness (one subject) at day 15; Moderate and severe itching (one subject each), Mild oiliness (3 subjects) and moderate oiliness (one subject) at day 30 . At day 60 , no site application reaction was noted by the dermatologists or perceived by the subjects and the product was considered overall safe.

There was improvement in fine lines and wrinkles (dermatological assessment and Visioscan) (Figure 1), lateral crow's feet (Figure 2), evenness of skin tone, Chromameter luminance ( $\mathrm{L}^{*}$ Value) at cheek and forehead (Figure 3), skin firmness/laxity (dermatological assessment and Cutometer) (Figure 4), hydration of skin (Figure 5), homogenecity of age spots (Figure 6), and visible pores (Figure 7). A good proportion of subjects felt improvement in several parameters (Figure 8). Representative images showing improvement are given in Figure 9, Figure 10, and Figure 11.

\section{Discussion}

The study met its both primary and second objectives of efficacy and safety. Twice daily application of serum containing growth factors and cytokines for a period of 90 days in 38 healthy Indian females was safe and well tolerated. Application site reactions were not clinically significant and disappeared completely by day 60 . Cutisera ${ }^{\mathrm{TM}}$ application considerably improved tested anti-ageing parameters. The improvement was perceived starting from day 15 onwards (crow's feet and hydration statistically significant at day 15) and continued over the course of study. The subjective assessments corroborated with dermatological 


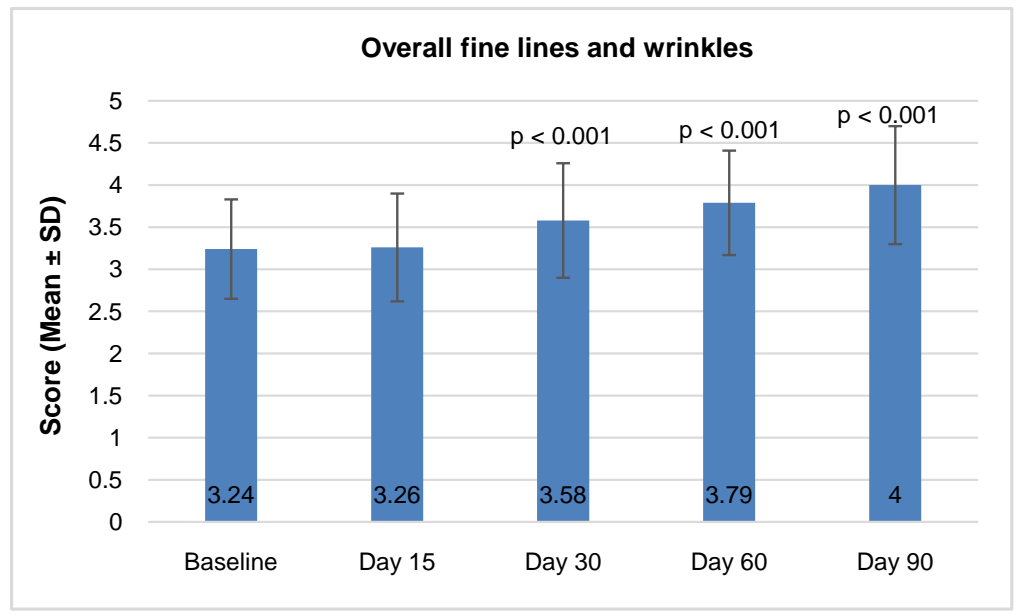

(a)

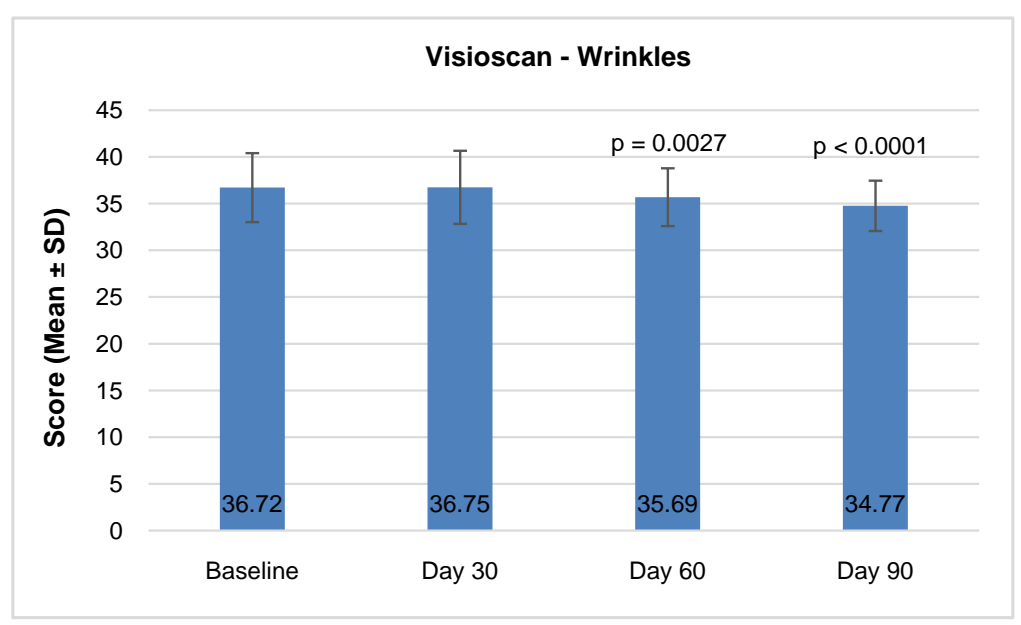

(b)

Figure 1. Fine lines and wrinkles. (a) Dermatological assessment: Day 30, 6090 vs. baseline: all $\mathrm{p}<0.001$. (b) Skin evaluation of wrinkles using Visioscan. Day 30 vs baseline: $\mathrm{p}=$ 0.8677 ; day 60 vs baseline: $\mathrm{p}=0.0027$; day 90 vs baseline: $\mathrm{p}<0.0001$.

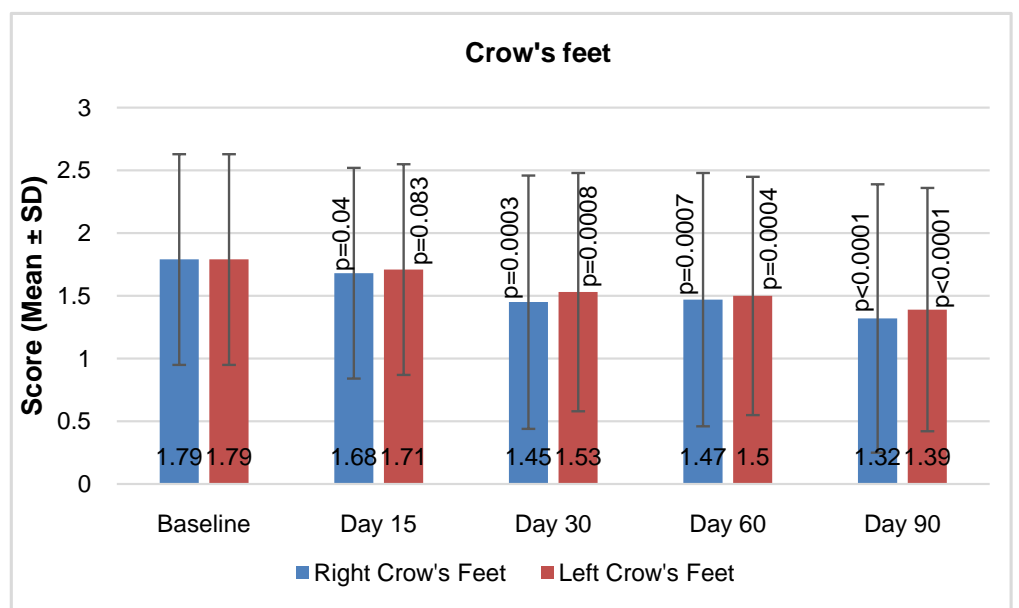

Figure 2. Crow's feet grading scale in unanimated face. Right Crow's feet: Day 15 vs. baseline: $p=0.0439$, day 30 vs. baseline: $p=0.0003$, day 60 vs. baseline: $p=0.0007$, day 90 vs. baseline: $p<0.0001$. Left Crow's feet: Day 15 vs. baseline: $p=0.0831$, day 30 vs. baseline: $\mathrm{p}=0.0008$, day 60 vs baseline: $\mathrm{p}=0.0004$, day 90 vs. baseline: $\mathrm{p}<0.0001$. 


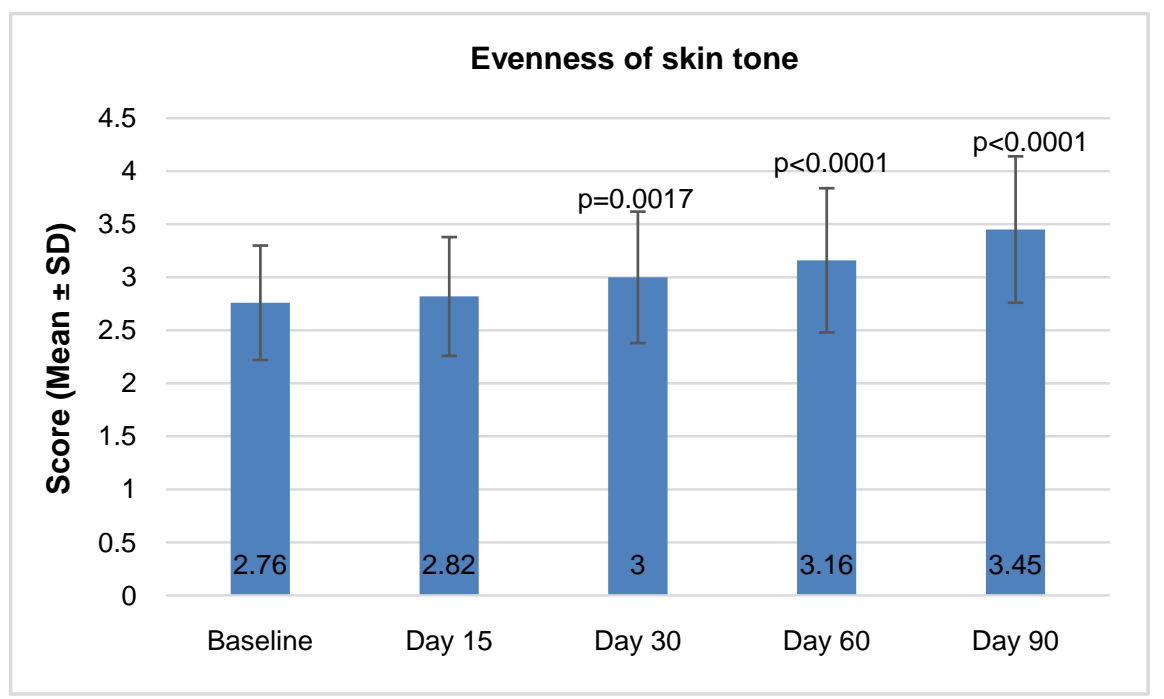

(a)

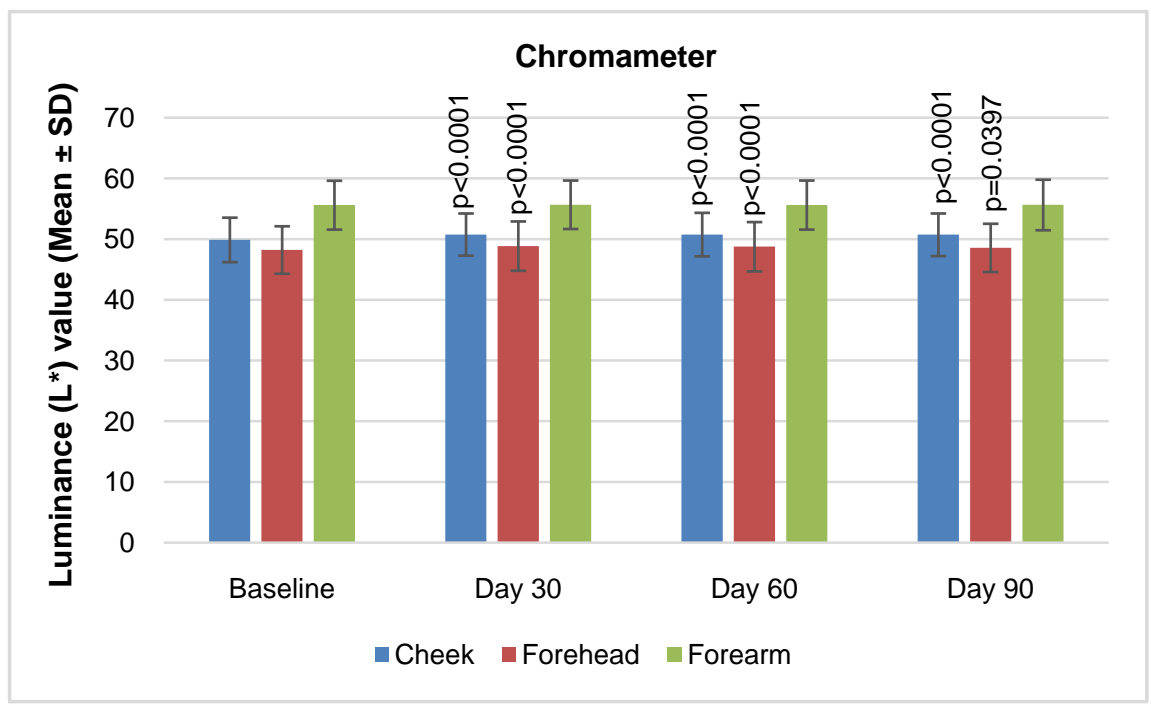

(b)

Figure 3. Crow's feet grading scale in unanimated face. Dermatological assessment. Day 15 vs. baseline: $p=0.16$; Day 30 vs. baseline: $p=0.0017$; Day 60 vs. baseline: $p<0.0001$; Day 90 vs. baseline: $\mathrm{p}<0.0001$. (b) Chroma meter measurement of luminescence. Cheek: Day 30 vs. baseline, day 60 vs baseline, day 90 vs baseline: all $\mathrm{p}<0.0001$; Forehead: Day 30 vs baseline, Day 60 vs baseline: $\mathrm{p}<0.0001$; Day 90 vs baseline: $\mathrm{p}=0.0397$.

assessment and measurements by instruments. Impaired capacity of skin to synthesize collagen thereby loosing elasticity and turgor occurs as a part of chronological ageing and photoageing. Stem cells release a host of bioactive factors and the same are found in abundance in the conditioned medium used for culturing these cells. Because of the host of factors released by stem cells into the medium, the condition medium is being evaluated as an alternative to stem cell based therapy for a variety of indications including skin conditions [5] [9] [10].

Natural extension of this application of therapy using conditioned medium is the treatment of aging. It is known that endogenous growth factors reduce with age [11]. Hence, administration of growth factors makes it logical for treatment 


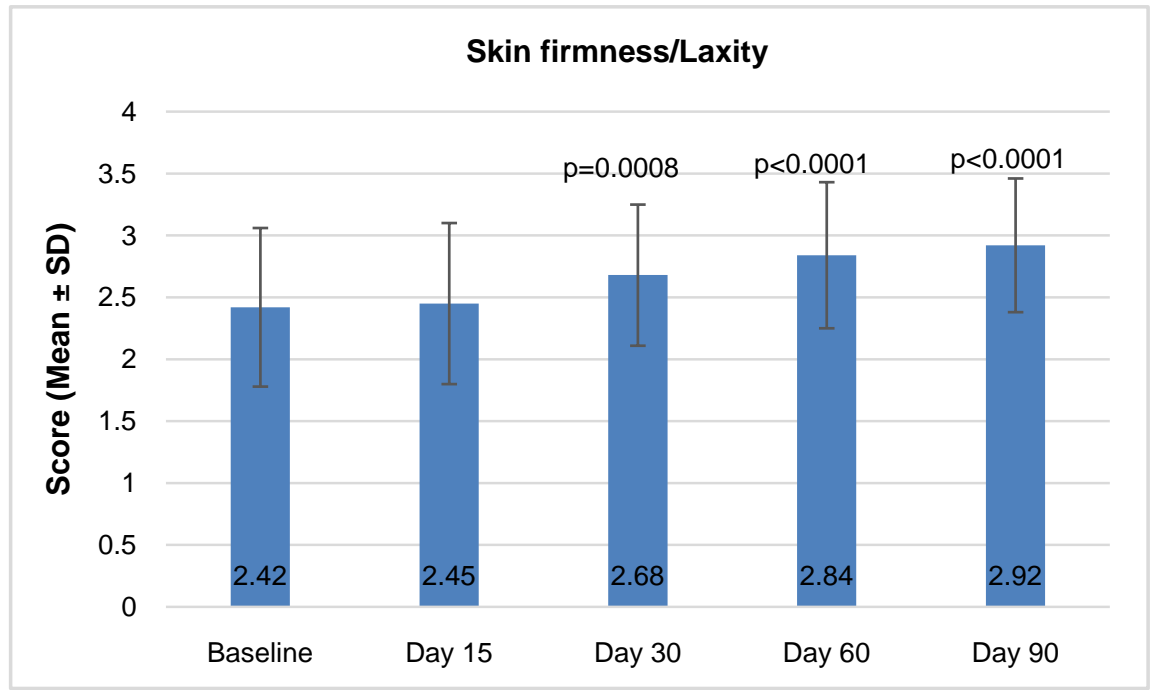

(a)

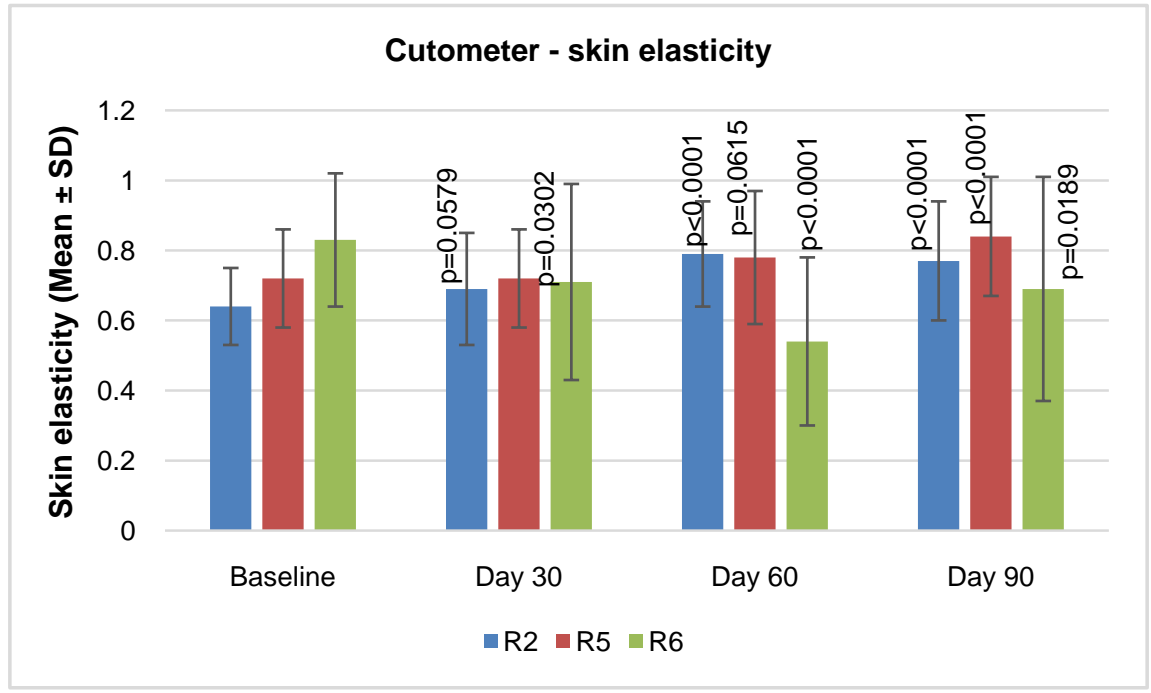

(b)

Figure 4. Skin firmness/laxity (a) Dermatological assessment of skin firmness/laxity. Day 15 vs baseline: $p=0.3238$; Day 30 vs baseline: $p=0.0008$; Day 60 vs baseline and Day 90 vs baseline: $\mathrm{p}<0.0001$. (b) Cutometer assessment of skin elasticity. R2: Day 30 vs baseline: $\mathrm{p}=0.0579$; Day 60 vs baseline and Day 90 vs baseline: both $\mathrm{p}<0.0001$; R5: Day 30 vs baseline: $\mathrm{p}=0.8053$; Day 60 vs baseline: $\mathrm{p}=0.0615$; Day 90 vs baseline: $\mathrm{p}<0.0001$; R6: Day 30 vs baseline: $\mathrm{p}=0.0302$; Day 60 vs baseline: $\mathrm{p}<0.0001$; Day 90 vs baseline: $\mathrm{p}=$ 0.0189 .

of skin aging. TGF beta causes increase in type I and type III collagen and plays a role in maintaining extracellular matrix [12]. Growth factors promote collagen synthesis, thus potentially benefit in rejuvenation [13] [14] [15]. Human growth factors are emerging as potential anti-aging agents [16] [17] [18].

The combination growth factors in Cutisera ${ }^{\mathrm{TM}}$ have shown benefit in skin aging in this study. The present study is similar to the study of growth factors administered along with a moisturizing cleanser and a sunscreen [19]. Clinical benefit in fine line and wrinkle was seen after three months of test product application compared to vehicle. Similar regime involving human epidermal 


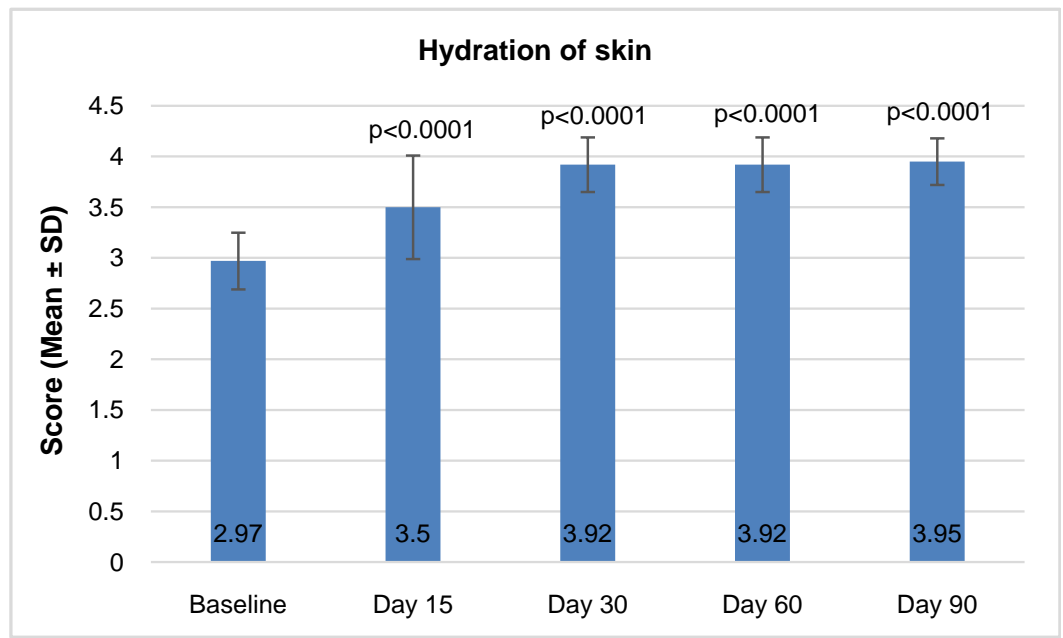

(a)

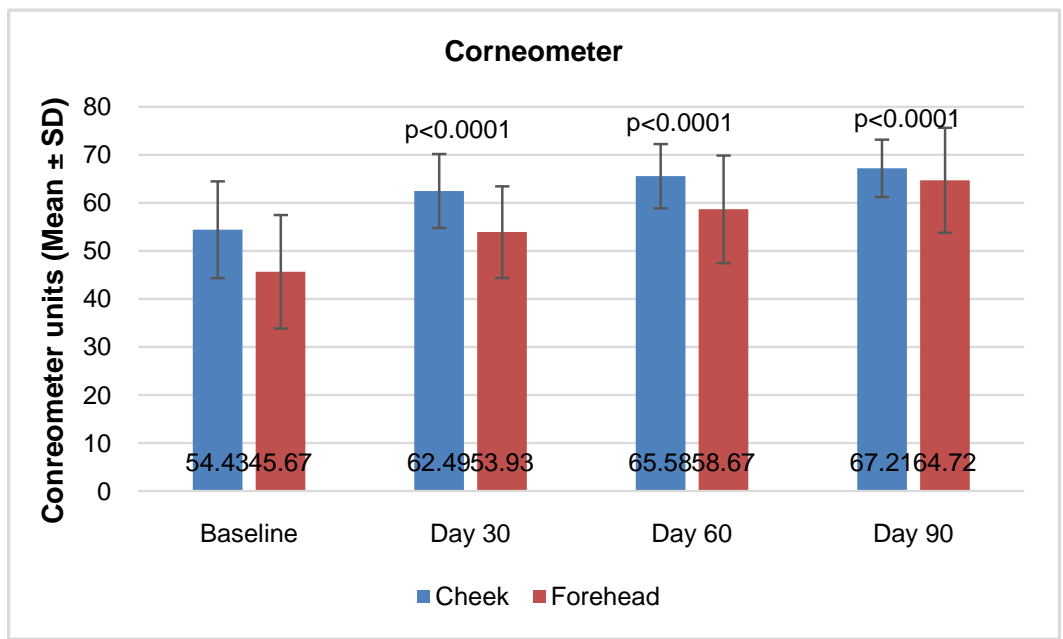

(b)

Figure 5. Skin hydration. (a) Dermatological assessment of hydration of skin. Day 15, 30, 60, 90 vs baseline: all $\mathrm{p}<0.0001$. (b) Corneometer assessment of skin hydration. Day 30, 60,90 vs baseline for cheek and forehead: all $\mathrm{p}<0.0001$.

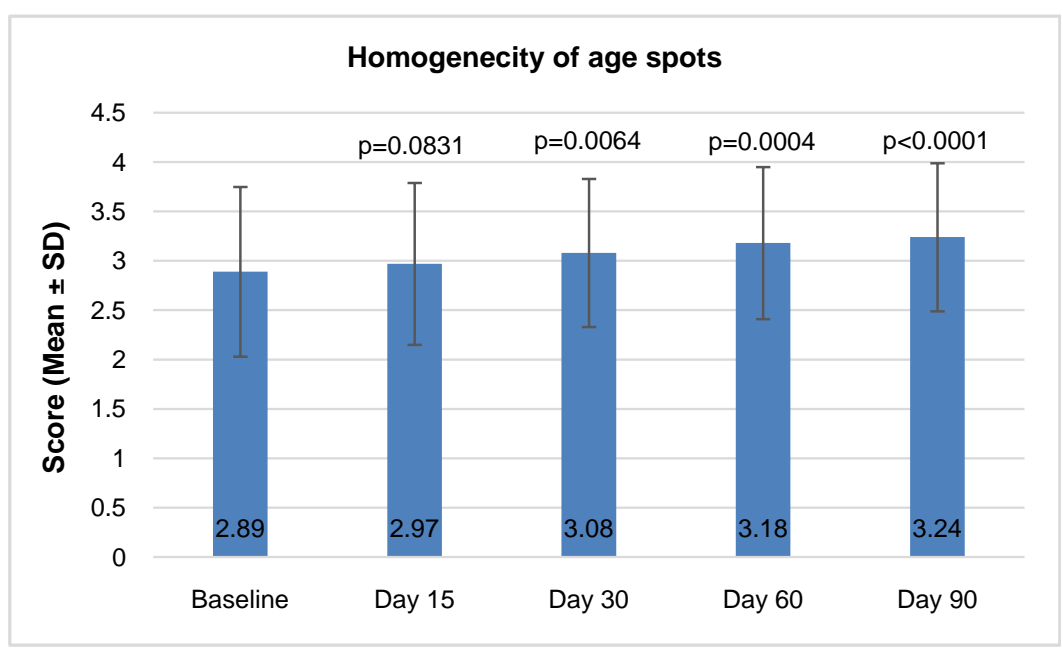

Figure 6. Homogenecity of Age-spots. Day 15 vs baseline: $p=0.0831$, Day 30 vs baseline: $\mathrm{p}=0.0064$; Day 60 vs baseline: $\mathrm{p}=0.0004$; Day 90 vs baseline: $\mathrm{p}<0.0001$. 


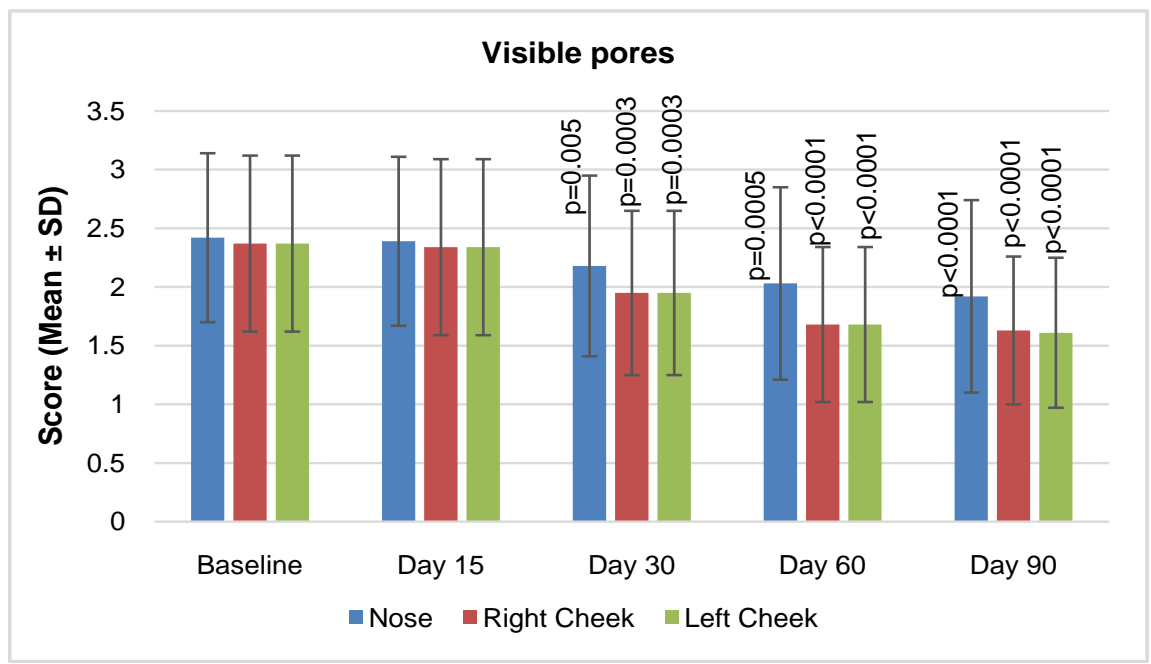

Figure 7. Dermatological assessment of visible pores. Day 15 vs baseline: $p=0.7108$; Day 30 vs baseline: $p=0.005$; Day 60 vs baseline: $p=0.0005$; Day 90 vs baseline: $p<0.0001$. Right cheek: Day 15 vs baseline: $p=0.7108$; Day 30 vs baseline: $p=0.0003$; Day 60 vs baseline and Day 90 vs baseline: $p<0.0001$. Left cheek: Day 15 vs baseline: $p=0.7108$; Day 30 vs baseline: $\mathrm{p}=0.0003$; Day 60 vs baseline and Day 90 vs baseline: $\mathrm{p}<0.0001$.

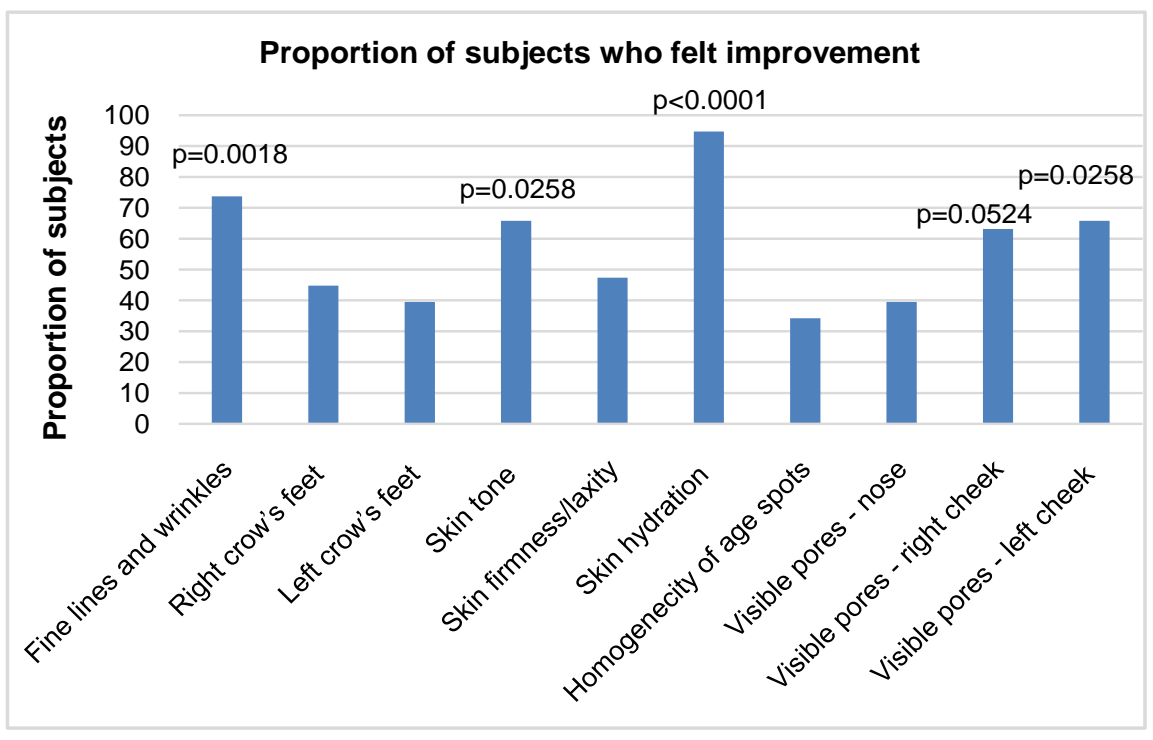

Figure 8. Assessment of improvements by subjects. Improvement in fine lines and wrinkles was felt by $73.68 \%$ subjects $(\mathrm{p}=0.0018)$; Improvement in skin tone was felt by $65.79 \%$ subjects $(\mathrm{p}=0.0258$ ); Improvement in skin hydration was felt by $94.74 \%$ subjects $(\mathrm{p}<0.0001)$; Improvement in visible pores was felt by $63.14 \%(\mathrm{p}=0.0524)$ and $65.79 \%(\mathrm{p}$ $=0.0258)$ subjects on right and left cheek respectively.

growth factor protein along with facial cleanser and sunscreen used for three months was effective in improving texture and appearance of facial skin [20].

Local application is a predominant route for delivering drugs for dermatological purposes. It is known that the stratum corneum is impermeable to molecules with high molecular weight [21]. In spite of high molecular weight, topically applied growth factors and cytokines provide clinical benefit. One possible explanation is that they pass through hair follicles, sweat glands and microlesions in 


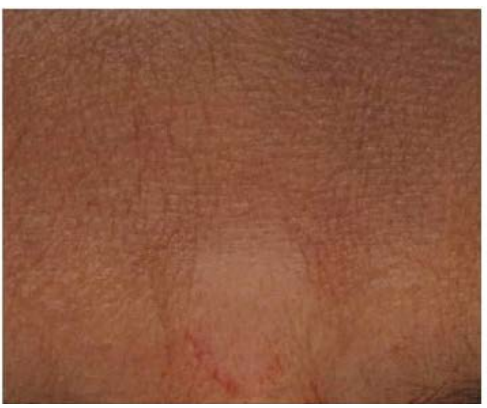

Baseline

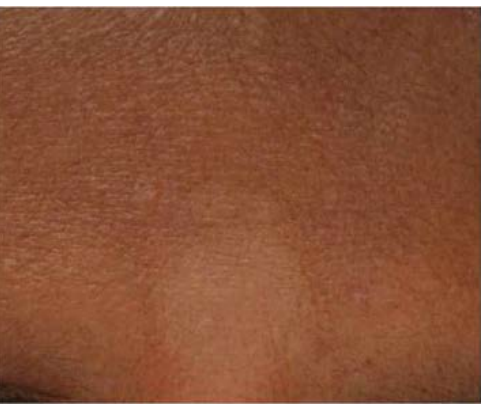

Day 90

(a)

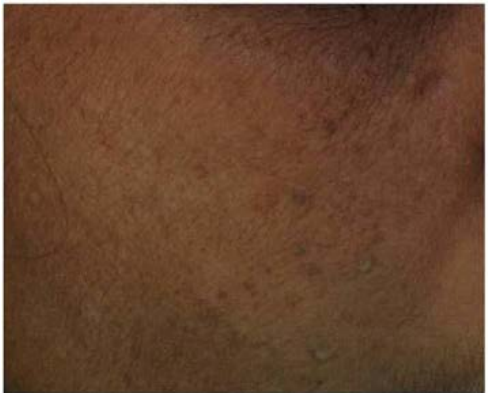

Baseline

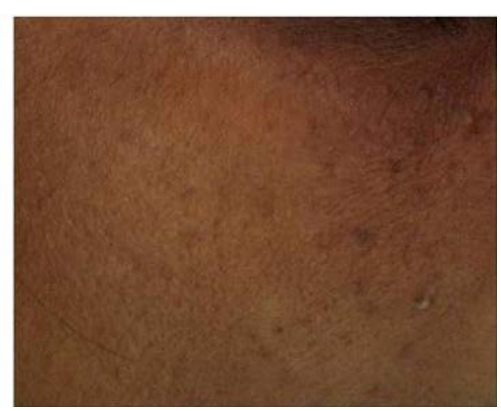

Day 90

(b)

Figure 9. Visible improvement in wrinkles, fine lines, skin tone. (a) Visible improvement in the wrinkles on the forehead (Frown Lines). (b): Visible improvement in overall wrinkles, fine lines in the under eye area, spots \& pigmentation and skin tone.

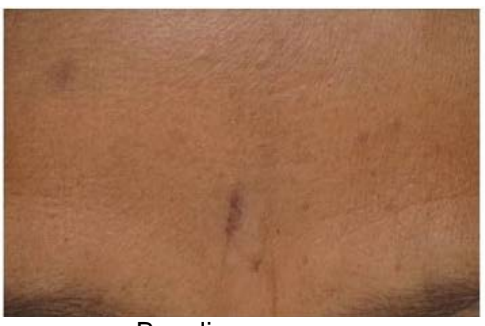

Baseline

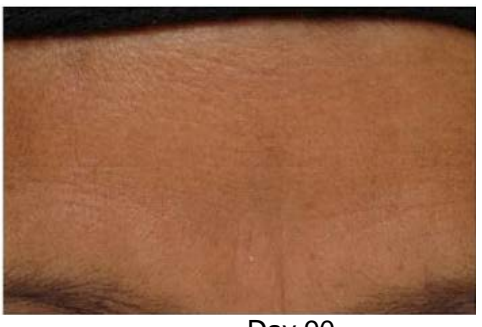

Day 90

Figure 10. Visible improvement in the skin clarity and skin tone.

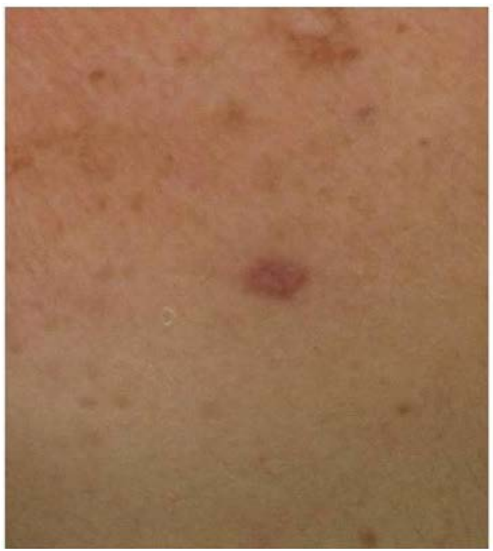

Baseline

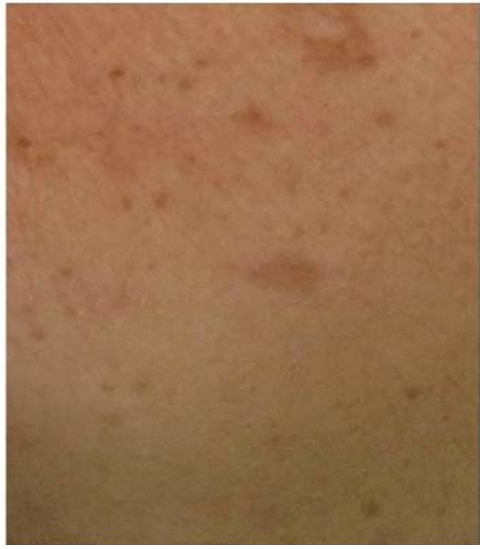

Day 90

Figure 11. Visible reduction in the spots and pigmentation. 
the interfollicular stratum corneum [22]. It is likely that small quantity reaching the stratum corneum binds to specific receptors to produce downstream signaling and may be clinically beneficial. In consequence, keratinocytes produce growth factors and initiate the effects on skin layers including collagen formation and strengthening of extracellular matrix.

Skin biopsy findings can provide evidence for mechanism of action. In a pilot study by Fitzpatrick et al., application of mixture of growth factors on photodamaged skin showed clinical improvement and suggestion of collagen formation on histopathology [23]. Increase in epidermal thickness and increased fibroblast density in dermis in addition to clinical benefits of wrinkle reduction was seen in a study by Hussain et al. [24]. In another study, application of adipose derived stem cells conditioned medium increased the synthesis of type I and III procollagen and elastin genes [9]. However, the study failed to show clinical efficacy, probably due to one-time administration of conditioned medium. Thus implying that daily (or twice daily) application of growth factors may be ideal for skin health.

Growth factors have been used either alone or in combination with other agents which complement the antiaging activity. A regimen containing six products including growth factor serum, cleanser, skin brightener, moisturizer, retinol, and sunscreen was found to be safe and efficacious in photodamage over face [25]. Growth factor combination product with or without l-ascorbic acid has been evaluated and the benefits were attributable to TGF beta [26]. Growth factors have been combined with hyaluronic acid and evaluated as anti-aging therapies [27] [28]. Mixture of growth factors and hyaluronic acid has been studied in conjunction with laser for skin rejuvenation with positive outcome [29].

Microneedling can facilitate entry of various agents in to the skin including growth factors. A novel method of combining microneedle fractional radiofrequency and conditioned medium in skin aging demonstrated clinical benefit and increase in dermal collagen content [30]. Subsequently, Lee et al. reported benefit of delivering growth factors through $0.25 \mathrm{~mm}$ microneedle for skin rejuvenation in a randomized, blinded study [31].

Current study has few limitations: Firstly, it lacked a placebo group. Secondly, multiple dose levels might have identified minimal effective dose and the dose (if any) after which the response plateaus. Third, there was no wash out period before the final assessment which might have shown persistence of effect (if any) after cessation of application. Fourth, we did not conduct skin biopsy which might have provided insights into structural changes.

\section{Conclusion}

The current study establishes the efficacy of a test serum containing growth factors and cytokines as an anti-ageing and rejuvenating modality in people with all skin types without any major side effects. Such topical products can be successfully used as either an alternative or as an adjunct to invasive rejuvenation procedures such as laser resurfacing. Combining topical growth factors with inva- 
sive rejuvenation procedures may improve recovery time and provide a synergistic effect on skin rejuvenation.

\section{Acknowledgements}

This study was funded by Stempeutics Research Private Limited, Bangalore, India. Dr. Madhumita Panda and Dr. Jaideep Gogtay of Cipla Ltd. contributed in the protocol development.

\section{References}

[1] Cevenini, E., Invidia, L., Lescai, F., Salvioli, S., Tieri, P., Castellani, G. and Franceschi, C. (2008) Human Models of Aging and Longevity. Expert Opinion on Biological Therapy, 8, 1393-1405. https://doi.org/10.1517/14712598.8.9.1393

[2] Gragnani, A., Cornick, S.M., Chominski, V., de Noronha, S.M.R., de Noronha, S.A.A.C. and Ferreira, L.M. (2014) Review of Major Theories of Skin Aging. Advances in Aging Research, 3, 265-284. https://doi.org/10.4236/aar.2014.34036

[3] Leyden, J.J. (1990) Clinical Features of Ageing Skin. British Journal of Dermatology, 122, 1-3. https://doi.org/10.1111/j.1365-2133.1990.tb16118.x

[4] Baumann, L. (2007) Skin Ageing and Its Treatment. The Journal of Pathology, 211, 241-251. https://doi.org/10.1002/path.2098

[5] Jayaraman, P., Nathan, P., Vasanthan, P., Musa, S. and Govindasamy, V. (2013) Stem Cells Conditioned Medium: A New Approach to Skin Wound Healing Management. Cell Biology International, 37, 1122-1128. https://doi.org/10.1002/cbin.10138

[6] Park, B.-S., Jang, K.A., Sung, J.-H., Park, J.-S., Kwon, Y.H., Kim, K.J. and Kim, W.-S. (2008) Adipose-Derived Stem Cells and Their Secretory Factors as a Promising Therapy for Skin Aging. Dermatologic Surgery, 34, 1323-1326.

[7] Kim, W.-S., Park, B.-S., Kim, H.-K., Park, J.-S., Kim, K.-J., Choi, J.-S., Chung, S.-J., Kim, D.-D. and Sung, J.-H. (2008) Evidence Supporting Antioxidant Action of Adipose-Derived Stem Cells: Protection of Human Dermal Fibroblasts from Oxidative Stress. Journal of Dermatological Science, 49, 133-142. https://doi.org/10.1016/j.jdermsci.2007.08.004

[8] Sze, S.K., de Kleijn, D.P.V., Lai, R.C., Khia Way Tan, E., Zhao, H., Yeo, K.S., Low, T.Y., Lian, Q., Lee, C.N., Mitchell, W., et al. (2007) Elucidating the Secretion Proteome of Human Embryonic Stem Cell-Derived Mesenchymal Stem Cells. Molecular \& Cellular Proteomics, 6, 1680-1689. https://doi.org/10.1074/mcp.M600393-MCP200

[9] Zhou, B.-R., Xu, Y., Guo, S.-L., Xu, Y., Wang, Y., Zhu, F., Permatasari, F., Wu, D., Yin, Z.-Q. and Luo, D. (2013) The Effect of Conditioned Media of Adipose-Derived Stem Cells on Wound Healing after Ablative Fractional Carbon Dioxide Laser Resurfacing. BioMed Research International, 2013, Article ID: 519126. https://doi.org/10.1155/2013/519126

[10] Kim, J.Y., Song, S.-H., Kim, K.L., Ko, J.-J., Im, J.-E., Yie, S.W., Ahn, Y.K., Kim, D.-K. and Suh, W. (2010) Human Cord Blood-Derived Endothelial Progenitor Cells and Their Conditioned Media Exhibit Therapeutic Equivalence for Diabetic Wound Healing. Cell Transplantation, 19, 1635-1644. https://doi.org/10.3727/096368910X516637

[11] Mori, Y., Hatamochi, A., Arakawa, M. and Ueki, H. (1998) Reduced Expression of mRNA for Transforming Growth Factor Beta (TGF Beta) and TGF Beta Receptors I 
and II and Decreased TGF Beta Binding to the Receptors in In Vitro-Aged Fibroblasts. Archives of Dermatological Research, 290, 158-162. https://doi.org/10.1007/s004030050282

[12] Varga, J., Rosenbloom, J. and Jimenez, S.A. (1987) Transforming Growth Factor Beta (TGF Beta) Causes a Persistent Increase in Steady-State Amounts of Type I and Type III Collagen and Fibronectin mRNAs in Normal Human Dermal Fibroblasts. Biochemical Journal, 247, 597-604. https://doi.org/10.1042/bj2470597

[13] Lee, E.Y., Xia, Y., Kim, W.-S., Kim, M.H., Kim, T.H., Kim, K.J., Park, B.-S. and Sung, J.-H. (2009) Hypoxia-Enhanced Wound-Healing Function of Adipose-Derived Stem Cells: Increase in Stem Cell Proliferation and Up-Regulation of VEGF and bFGF. Wound Repair and Regeneration, 17, 540-547.

https://doi.org/10.1111/j.1524-475x.2009.00499.x

[14] Lee, M.J., Kim, J., Lee, K.I., Shin, J.M., Chae, J.I. and Chung, H.M. (2011) Enhancement of Wound Healing by Secretory Factors of Endothelial Precursor Cells Derived from Human Embryonic Stem Cells. Cytotherapy, 13, 165-178. https://doi.org/10.3109/14653249.2010.512632

[15] Hagerty, P., Lee, A., Calve, S., Lee, C.A., Vidal, M. and Baar, K. (2012) The Effect of Growth Factors on Both Collagen Synthesis and Tensile Strength of Engineered Human Ligaments. Biomaterials, 33, 6355-6361. https://doi.org/10.1016/j.biomaterials.2012.05.045

[16] Mehta, R.C. and Fitzpatrick, R.E. (2007) Endogenous Growth Factors as Cosmeceuticals. Dermatologic Therapy, 20, 350-359. https://doi.org/10.1111/j.1529-8019.2007.00149.x

[17] Sundaram, H., Mehta, R.C., Norine, J.A., Kircik, L., Cook-Bolden, F.E., Atkin, D.H., Werschler, P.W. and Fitzpatrick, R.E. (2009) Topically Applied Physiologically Balanced Growth Factors: A New Paradigm of Skin Rejuvenation. Journal of Drugs in Dermatology, 8, 4-13.

[18] Fabi, S. and Sundaram, H. (2014) The Potential of Topical and Injectable Growth Factors and Cytokines for Skin Rejuvenation. Facial Plastic Surgery, 30, 157-171. https://doi.org/10.1055/s-0034-1372423

[19] Mehta, R.C., Smith, S.R., Grove, G.L., Ford, R.O., Canfield, W., Donofrio, L.M., Flynn, T.C. and Leyden, J.J. (2008) Reduction in Facial Photodamage by a Topical Growth Factor Product. Journal of Drugs in Dermatology, 7, 864-871.

[20] Schouest, J.M., Luu, T.K. and Moy, R.L. (2012) Improved Texture and Appearance of Human Facial Skin after Daily Topical Application of Barley Produced, Synthetic, Human-Like Epidermal Growth Factor (EGF) Serum. Journal of Drugs in Dermatology, 11, 613-620.

[21] Andrews, S.N., Jeong, E. and Prausnitz, M.R. (2013) Transdermal Delivery of Molecules Is Limited by Full Epidermis, Not Just Stratum Corneum. Pharmaceutical Research, 30, 1099-1109. https://doi.org/10.1007/s11095-012-0946-7

[22] Schaefer, H. and Lademann, J. (2001) The Role of Follicular Penetration. A Differential View. Skin Pharmacology and Applied Skin Physiology, 14, 23-27. https://doi.org/10.1159/000056386

[23] Fitzpatrick, R.E. and Rostan, E.F. (2003) Reversal of Photodamage with Topical Growth Factors: A Pilot Study. Journal of Cosmetic and Laser Therapy, 5, 25-34.

[24] Hussain, M., Phelps, R. and Goldberg, D.J. (2008) Clinical, Histologic, and Ultrastructural Changes after Use of Human Growth Factor and Cytokine Skin Cream for the Treatment of Skin Rejuvenation. Journal of Cosmetic and Laser Therapy, 10, 104-109. https://doi.org/10.1080/14764170701885392

[25] Herndon, J.H., Makino, E.T., Jiang, L.I., Stephens, T.J. and Mehta, R.C. (2015) 
Long-Term Multi-Product Facial Regimen in Subjects with Moderate-to-Severe Photodamage and Hyperpigmentation. The Journal of Clinical and Aesthetic Dermatology, 8, 16-21.

[26] Ehrlich, M., Rao, J., Pabby, A. and Goldman, M.P. (2006) Improvement in the Appearance of Wrinkles with Topical Transforming Growth Factor Beta(1) and 1-Ascorbic Acid. Dermatologic Surgery, 32, 618-625.

[27] Lupo, M.L., Cohen, J.L. and Rendon, M.I. (2007) Novel Eye Cream Containing a Mixture of Human Growth Factors and Cytokines for Periorbital Skin Rejuvenation. Journal of Drugs in Dermatology, 6, 725-729.

[28] Trookman, N.S., Rizer, R.L., Ford, R., Ho, E. and Gotz, V. (2009) Immediate and Long-Term Clinical Benefits of a Topical Treatment for Facial Lines and Wrinkles. The Journal of Clinical and Aesthetic Dermatology, 2, 38-43.

[29] Gold, M.H., Katz, B.E., Cohen, J.L. and Biron, J. (2010) Human Growth Factor Cream and Hyaluronic Acid Serum in Conjunction with Micro Laser Peel: An Efficient Regimen for Skin Rejuvenation. The Journal of Clinical and Aesthetic Dermatology, 3, 37-42.

[30] Seo, K.Y., Kim, D.H., Lee, S.E., Yoon, M.S. and Lee, H.J. (2013) Skin Rejuvenation by Microneedle Fractional Radiofrequency and a Human Stem Cell Conditioned Medium in Asian Skin: A Randomized Controlled Investigator Blinded Split-Face Study. Journal of Cosmetic and Laser Therapy, 15, 25-33. https://doi.org/10.3109/14764172.2012.748201

[31] Lee, H.J., Lee, E.G., Kang, S., Sung, J.-H., Chung, H.-M. and Kim, D.H. (2014) Efficacy of Microneedling plus Human Stem Cell Conditioned Medium for Skin Rejuvenation: A Randomized, Controlled, Blinded Split-Face Study. Annals of Dermatology, 26, 584-591. https://doi.org/10.5021/ad.2014.26.5.584

\section{Submit or recommend next manuscript to SCIRP and we will provide best} service for you:

Accepting pre-submission inquiries through Email, Facebook, LinkedIn, Twitter, etc. A wide selection of journals (inclusive of 9 subjects, more than 200 journals)

Providing 24-hour high-quality service

User-friendly online submission system

Fair and swift peer-review system

Efficient typesetting and proofreading procedure

Display of the result of downloads and visits, as well as the number of cited articles

Maximum dissemination of your research work

Submit your manuscript at: http://papersubmission.scirp.org/

Or contact jcdsa@scirp.org 